\title{
Synthesis and Properties of Polyarylates Derived from 4,4"-Dihydroxy-o-terphenyl
}

\author{
Fumihiko AKutsu, ${ }^{\dagger}$ Mari Inoki, Ken-ichi Takahashi, Taisuke Yonemura, \\ Yoshio KaSaSHIMA, and Kiyoshi NaRUCHI
}

Department of Applied Chemistry, Faculty of Engineering, Chiba University, Yayoi-cho 1-33, Inage-ku, Chiba 263, Japan

(Received June 11, 1996)

KEY WORDS Polyarylates / 4,4"-Dihydroxy-o-terphenyl / Solubility / Thermal Properties /

Aromatic polyesters (polyarylates) are well known as high-performance engineering thermoplastics. The polyarylates are applied in various industries as coatings, composites, molded components, toughening agents, for their high thermal stability, good mechanical properties, and inert behavior forward organic solvents. ${ }^{1,2}$ However, as they need high fabricating temperature and exhibit poor solubility in organic solvents, improvement of the processability is required. But, the improvement of solubility is often accompanied by lowering thermal stability.

In this article, the synthesis and properties of novel polyarylates introduced 4,4 "-o-terphenyldiyl structure to the main chains were investigated. We previously reported that the the introduction of rigid and zigzag 4,4 "$o$-terphenyldiyl structure to the main chains of aromatic polyamides, ${ }^{3,4}$ polyimides, ${ }^{4}$ and polyethers ${ }^{5}$ leads to improvements of solubility, maintaining high thermal stability, and the polymers are all amorphous. Different from those polyamides, polyimides, and polyethers, some polyarylates containing 4,4"-o-terphenyldiyl structure exhibited the semi-crystalline nature.

\section{RESULTS AND DISCUSSION}

Polyarylates $2 \mathbf{2 a}-\mathbf{d}$ were prepared from 4,4"-dihydro$\mathrm{xy}-o$-terphenyl (DHOTP $)^{5,6}$ and aromatic dicarbonyl dichlorides $1 \mathbf{a}-\mathbf{d}$ by interfacial polycondensation in an organic solvent-aqueous alkaline solution system using benzyltriethylammonium chloride (BTEAC) or sodium laurylsulfate (SLS) as a phase transfer catalyst, ${ }^{7}$ as shown in Scheme 1. Interfacial polycondensation is largely affected by the organic solvent and catalyst. Thus, organic solvents were investigated in the synthesis of $2 \mathbf{a}$. Acetophenone, nitrobenzene, chloroform, and dichloromethane were used as organic solvents. Dichloromethane was the most suitable for the polycondensation of DHOTP and 1a, and the inherent viscosity of polyarylate $\mathbf{2 a}$, obtained from this reaction system, was highest. The value was $0.71 \mathrm{dlg}^{-1}$. BTEAC was more effective than SLS as a phase transfer catalyst in this reaction system. Other polycondensations were carried out in dichloromethane-aqueous $\mathrm{NaOH}$ solution using BTEAC as the catalyst. Polyarylates $\mathbf{2}$ were given almost quantitatively. As $\mathbf{2 a}, \mathbf{2 b}$, and $\mathbf{2 d}$ were soluble in the mixed solvent of $o$-dichlorobenzene/phenol, of which the ratio was $40 / 60$ by weight, inherent viscosity was measured, and to range from 0.24 to $0.71 \mathrm{dl} \mathrm{g}^{-1}$. An inherent viscosity of $2 \mathrm{c}$ could not be measured, being insoluble in all common organic solvents. The results are summarized in Table I. The inherent viscosity in run 10 of Table I was lower though 4,4 '-sulfonyldibenzoyl dichloride having higher reactivity was used as the monomer. This may be attributed to the partial hydrolysis of the acyl-chloride group by higher reactivity.

The solubilities of polyarylates 2 in various organic solvents at $2.0 \%(\mathrm{w} / \mathrm{v})$ were examined. The solubilities are tabulated in Table II. 2a indicated high solubility; it was soluble in anisole, acetophenone, and $m$-cresol at room temperature, and pyridine and 1-methyl-2pyrolidone (NMP) at $60^{\circ} \mathrm{C}$. 2a was soluble in anisole up to $10 \%(\mathrm{w} / \mathrm{v})$ at room temperature. $2 \mathrm{~d}$ was soluble in

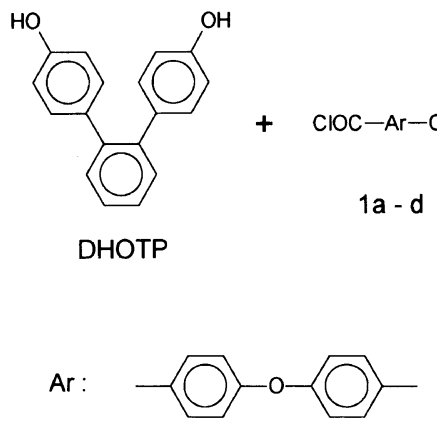

a

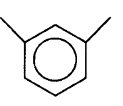

b

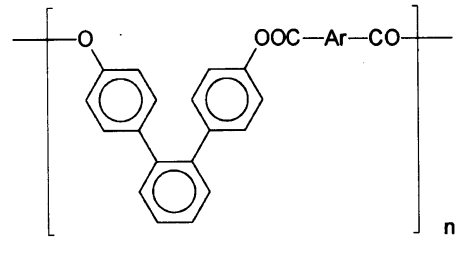

$2 a-d$

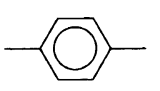

C

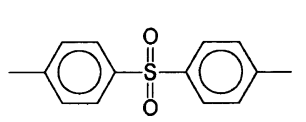

d

Scheme 1.

\footnotetext{
$\uparrow$ To whom correspondence should be addressed.
} 
common organic solvents at room temperature. But, $2 \mathbf{b}$ was soluble in NMP at $60^{\circ} \mathrm{C}$ alone. $2 \mathrm{c}$ was even insoluble in a mixed solvent of $o$-dichlorobenzene/phenol. Thus, $\mathbf{2 a}$ and $\mathbf{2 d}$ indicated good solubility, but $\mathbf{2 b}$ and $\mathbf{2 c}$, poor solubility. The introduction of the $4,4^{\prime \prime}-o$-terphenyldiyl structure improved the solubility of polyarylates, but, the improvement was less than for the polyamides, polyimides, and polyethers.

The temperatures at $5 \%$ weight loss $\left(T_{\mathrm{d}} \mathrm{s}\right)$ and residual weight were determined by thermogravimetry (TG). Glass-transition temperatures $\left(T_{\mathrm{g}} \mathrm{s}\right)$ were determined by differential scanning calorimetry (DSC). The thermal properties of $\mathbf{2}$ are shown in Table III. $T_{\mathrm{d}} \mathrm{s}$ of $\mathbf{2}$ were high, from 458 to $478^{\circ} \mathrm{C}$. Residual weight at $600^{\circ} \mathrm{C}$ ranged between 49 and $58 \%$. Thus, polyarylates 2 indicated high thermal stability. $T_{\mathrm{g}} \mathrm{s}$ of polyarylates 2 ranged from 186 to $239^{\circ} \mathrm{C}$. $T_{\mathrm{g}}$ of $2 \mathrm{a}$ having inherent visicosity of $0.71 \mathrm{dl} \mathrm{g}^{-1}$ was $201{ }^{\circ} \mathrm{C}$, but that having inherent viscosity of 0.29 $\mathrm{dl} \mathrm{g}^{-1}$ was $139^{\circ} \mathrm{C}$. DSC curves of $\mathbf{2 b}$ and $\mathbf{2 c}$ indicated melting points $\left(T_{\mathrm{m}} \mathrm{s}\right)$ at $308^{\circ} \mathrm{C}$ and at $390^{\circ} \mathrm{C}$, respectively. Maintaining high thermal stability was attributed to the rigidity of the $4,4^{\prime \prime}$ - $o$-terphenyldiyl structure.

The X-ray diffraction patterns showed that $2 \mathbf{a}$ and $\mathbf{2 d}$ are amorphous polymers, but $\mathbf{2 b}$ and $\mathbf{2 c}$ are semicrystalline, unexpectedly, as shown in Figure 1. In many cases, aromatic polyarylates indicate a crystalline nature. But, we previously reported aromatic polyamides, ${ }^{3,4}$ polyimides, ${ }^{4}$ and polyethers ${ }^{5}$ containing the 4,4 " $-o$-ter-

Table I. Results of preparations of polyesters $2 \mathbf{a}-\mathbf{d}^{\mathbf{a}}$

\begin{tabular}{|c|c|c|c|c|c|}
\hline \multirow{2}{*}{ Run } & \multirow{2}{*}{ Polyester } & \multirow{2}{*}{ Solvent } & \multirow{2}{*}{ Catalyst } & \multirow{2}{*}{$\frac{\text { Yield }}{\%}$} & \multirow{2}{*}{$\frac{\eta_{\mathrm{inh}}^{\mathrm{b}}}{\left(\mathrm{dl} \mathrm{g}^{-1}\right)}$} \\
\hline & & & & & \\
\hline 1 & $2 \mathbf{a}$ & $\mathrm{AcPH}^{\mathrm{c}}$ & BTEAC $^{d}$ & 88 & 0.13 \\
\hline 2 & $2 a$ & $\mathrm{C}_{6} \mathrm{H}_{5} \mathrm{NO}_{2}$ & BTEAC & 86 & 0.13 \\
\hline 3 & $2 a$ & $\mathrm{CHCl}_{3}$ & BTEAC & 89 & 0.29 \\
\hline 4 & $2 a$ & $\mathrm{CH}_{2} \mathrm{Cl}_{2}$ & BTEAC & 93 & 0.71 \\
\hline 5 & $2 a$ & $\mathrm{CH}_{2} \mathrm{Cl}_{2}$ & SLS $^{\mathrm{e}}$ & 87 & 0.29 \\
\hline 6 & $2 a$ & $\mathrm{CHCl}_{3}$ & SLS & 88 & 0.12 \\
\hline 7 & $2 \mathbf{b}$ & $\mathrm{CH}_{2} \mathrm{Cl}_{2}$ & BTEAC & 90 & 0.34 \\
\hline 8 & $2 b$ & $\mathrm{CHCl}_{3}$ & BTEAC & 72 & 0.12 \\
\hline 9 & $2 c$ & $\mathrm{CH}_{2} \mathrm{Cl}_{2}$ & BTEAC & 93 & $-^{\mathrm{f}}$ \\
\hline 10 & 2d & $\mathrm{CH}_{2} \mathrm{Cl}_{2}$ & BTEAC & 98 & 0.24 \\
\hline
\end{tabular}

a Polymerization was carried out with $1.25 \mathrm{mmol}$ of each monomer and $7.5 \mathrm{mg}$ catalyst in $4.5 \mathrm{ml}$ organic solvent and $2.6 \mathrm{ml} 1 \mathrm{M}$ aqueous sodium hydroxide at room temperature for $40 \mathrm{~min}$. ${ }^{\mathrm{b}}$ Inherent viscosity, measured in $o$-dichlorobenzene/phenol ( $40 / 60$ by weight) $\left(0.50 \mathrm{~g} \mathrm{dl}^{-1}\right)$ at $30^{\circ} \mathrm{C}$. ${ }^{\mathrm{c}} \mathrm{AcPH}$, acetophenone. ${ }^{\mathrm{d}} \mathrm{BTEAC}$, benzyltriethylammonium chloride. ${ }^{\mathrm{e}} \mathrm{SLS}$, sodium laurylsulfate. ${ }^{\mathrm{f}}$ Inherent viscosity could not be measured because the obtained polymer was not soluble in the solvents. phenyldiyl structure to be amorphous, and polyarylates containing 2,3-quinoxalinediyl ${ }^{8}$ or 4,5-imidazolediyl structure, ${ }^{9}$ similar to $4,4 "-o$-terphenyldiyl structure, to be amorphous. The composition of an ester linkage, $4,4^{\prime \prime}$-o-terphenyldiyl structure, and 1,3-phenylene or 1,4-phenylene structure in the molecular chain may be more favorable for crystal formation. The semi-crystalline nature may contribute to the low solubility and indicating melting points of $\mathbf{2} \mathbf{b}$ and $\mathbf{2 c}$. Improved solubility and the amorphous nature of $2 \mathbf{a}$ and $\mathbf{2 d}$ were due to the introduction of a zigzag $o$-terphenyl structure as well as an ether linkage or sulfone linkage to the main chains of polyarylates, because the solubility of polyarylates cannot be improved only by the introduction of an ether ${ }^{10}$ or sulfone linkage ${ }^{11}$ to the main chains. Nisahizaki et al. reported a polyarylate derived from $4,4^{\prime}$-oxydibenzoyl dichloride and hydroquinone to be insoluble in many organic solvents at $1.0 \%(\mathrm{w} / \mathrm{v}) .{ }^{10}$ Manami et al. reported that a polyarylate $4,4^{\prime}$-sulfonyldibenzoic acid and hydroquinone indicated insolubility in the many organic solvents. ${ }^{11}$

It is concluded that the polyarylates $\mathbf{2 a}$ and $\mathbf{2 d}$ have improved good solubility, while maintaining high thermal stability due to the effects of the introduction of rigid and zigzag 4,4"-o-terphenyldiyl units to the backbones of polyarylates. Polyarylates $\mathbf{2 b}$ and $\mathbf{2 c}$ indicated high thermal stability, but, exhibited low solubility and melting points, due to semi-crystalline features.

\section{EXPERIMENTAL}

\section{Monomers}

4,4'-Oxydibenzoyl dichloride (1a) and 4,4'-sulfonyldibenzoyl dichloride (1d) were obtained by the chlorination of the corresponding dicarboxylic acid with thionyl chloride. 1a was recrystallized from dry $n$-hexane. 1d was recrystallized from dry benzene. Isophthaloyl dichloride (1b) and terephthaloyl dichloride (1c) were commercially available and used after recrystallization. 4,4"-Dihydro$\mathrm{xy}-o$-terphenyl (DHOTP) was synthesized from $4,4^{\prime \prime}$ diamino- $o$-terphenyl ${ }^{4}$ as previously reported, ${ }^{5,6}$ and recrystallized once from benzene and once from toluene.

\section{Polycondensations}

A typical procedure is as follows: In a homogenizer equipped with a mechanical stirrer, DHOTP $(0.3279 \mathrm{~g}$, $1.25 \mathrm{mmol}$ ) was placed, and dissolved in $2.6 \mathrm{ml} 1 \mathrm{M}$ aqueous $\mathrm{NaOH}$ solution with stirring, and $7.5 \mathrm{mg}$ of BTEAC were added. A solution of $0.3689 \mathrm{~g}(1.25 \mathrm{mmol})$ of $1 \mathrm{a}$ in $4.5 \mathrm{ml}$ dichloromethane was added all at once with vigorous stirring. The reaction mixture was stirred for $40 \mathrm{~min}$ at room temperature, and poured into hot

Table II. Solubilities of polyarylates $\mathbf{2 a}-\mathbf{d}^{\mathbf{a}}$

\begin{tabular}{|c|c|c|c|c|c|c|c|c|}
\hline Run $^{b}$ & Polymer & Anisol & THF & $\mathrm{AcPH}$ & Py & $m$-Cre & DMAc & NMP \\
\hline 4 & $\mathbf{2 a}$ & + & \pm & + & $(+)$ & + & $( \pm)$ & $(+)$ \\
\hline 7 & $\mathbf{2 b}$ & \pm & \pm & \pm & \pm & \pm & \pm & $(+)$ \\
\hline 9 & $2 c$ & $( \pm)$ & - & $( \pm)$ & $( \pm)$ & $( \pm)$ & $( \pm)$ & $( \pm)$ \\
\hline 10 & $2 d$ & + & + & + & + & + & + & + \\
\hline
\end{tabular}

${ }^{a}$ Measured at $2.0 \%(\mathrm{w} / \mathrm{v})$. Data in parentheses were obtained during heating at $60^{\circ} \mathrm{C}$. THF, tetrahydrofuran; AcPH, acetophenone; Py, pyridine; $m$-Cre, $m$-cresol; DMAc, $N, N$-dimethylacetamide; NMP, 1-methyl-2-pyrrolidone. + , soluble; \pm , partially soluble; - , insoluble. ${ }^{b}$ Sample run numbers appear in Table I. 
Table III. Thermal properties of polyarylates $\mathbf{2 a - d}$

\begin{tabular}{|c|c|c|c|c|c|}
\hline \multirow{2}{*}{ Run $^{a}$} & \multirow{2}{*}{ Polyester } & $T_{\mathrm{g}}^{\mathrm{b}}$ & $T_{\mathrm{m}}^{\mathrm{c}}$ & $T_{\mathrm{d}}^{\mathrm{d}}$ & \multirow{2}{*}{$\begin{array}{c}\text { Residual weight } \\
\text { at } 600^{\circ} \mathrm{C} \\
1 \%{ }^{\circ}\end{array}$} \\
\hline & & ${ }^{\circ} \mathrm{C}$ & ${ }^{\circ} \mathrm{C}$ & ${ }^{\circ} \mathrm{C}$ & \\
\hline 4 & $2 a$ & $201(139)^{\mathrm{f}}$ & $\ldots \mathrm{g}$ & 477 & 58 \\
\hline 7 & 2b & 186 & 308 & 478 & 54 \\
\hline 9 & $2 c$ & 214 & 390 & 477 & 55 \\
\hline 10 & 2d & 239 & —g & 458 & 49 \\
\hline
\end{tabular}

${ }^{\text {a }}$ Sample run numbers appear in Table $\mathbf{I}$. ${ }^{\mathrm{b}}$ Glass transition temperature, measured by differential scanning calorimetry (DSC). ${ }^{\mathrm{c}}$ Melting point, measured by DSC. ${ }^{\mathrm{d}}$ Temperature at $5 \%$ weight loss in nitrogen atmosphere, determined by thermogravimetry (TG). ${ }^{\mathrm{e}} \mathrm{De}-$ termined by TG. ${ }^{\mathrm{f}}$ Data in parentheses for the sample in run 3 . ${ }^{\mathrm{g}}$ Not observed.

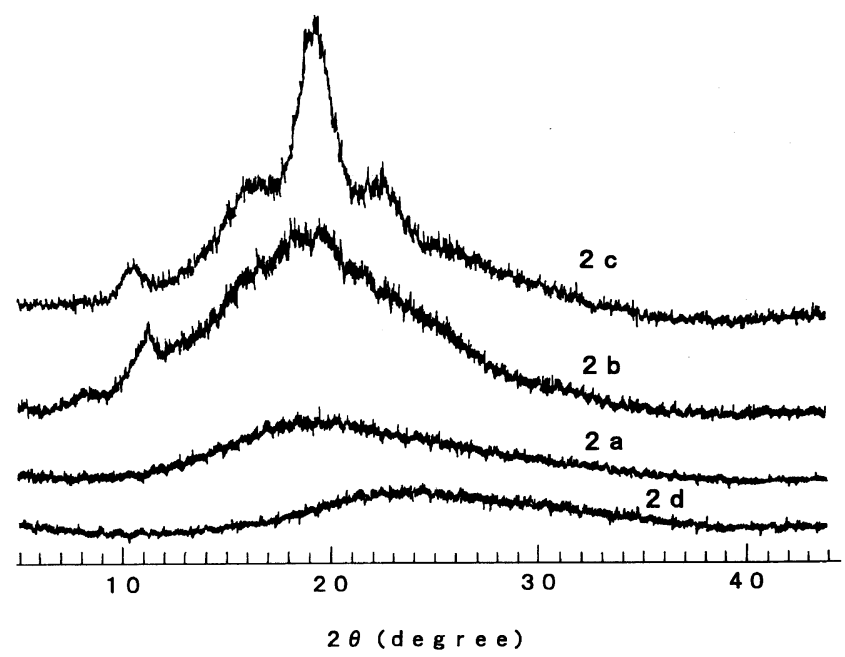

Figure 1. X-Ray diffraction patterns of polyarylates 2 .

water for precipitation. The products were collected by filtration with a glass filter, washed with hot methanol, and dried under reduced pressure at $60^{\circ} \mathrm{C}$. Yield $93.0 \%$.

$\eta_{\text {inh }}=0.71 \mathrm{dl} \mathrm{g}^{-1}\left(0.5 \mathrm{~g} \mathrm{dl}^{-1}\right.$ in $o$-dichlorobenzene $/$ phenol, $40 / 60$ by weight, at $\left.30^{\circ} \mathrm{C}\right)$. IR $(\mathrm{KBr}$, disk) 1736 $\mathrm{cm}^{-1}(\mathrm{C}=\mathrm{O}), 1246 \mathrm{~cm}^{-1}(\mathrm{C}-\mathrm{O})$.

Anal. Calcd for $\left(\mathrm{C}_{32} \mathrm{H}_{20} \mathrm{O}_{5}\right)_{n}(484.5)_{n}: \mathrm{C}, 79.33 \% ; \mathrm{H}$, $4.16 \%$. Found: C, $79.13 \%$; H, 4.16\%.
Other polyarylates were synthesized by a similar procedure.

\section{Measurements}

$T_{\mathrm{g}} \mathrm{s}$ and $T_{\mathrm{m}} \mathrm{s}$ were measured by DSC (Rigaku $8230 \mathrm{D}$ ) and second scannings. $T_{\mathrm{d}} \mathrm{s}$ and residual weight were determined by TG (Mac Science TG-DTA 2000). Measurements of DSC and TG were carried out under the following conditions: heating rate, $10 \mathrm{~K} \mathrm{~min}^{-1}$; in nitrogen atmosphere. IR spectra were recorded on a Hitachi 270-30 spectrophotometer. Wide angle X-ray diffraction patterns were obtained for specimens on a Rigaku Denki XG X-ray diffraction apparatus with $\mathrm{Cu}-K_{\alpha}$ radiation $(25 \mathrm{kV}, 10 \mathrm{~mA})$ using virgin samples.

Acknowledgments. The authors thank Mr. Tadao Kuramochi, Chemical Analysis Center, Chiba University, for conducting the elemental analysis. We are indebted to New Japan Chemical Co. Ltd., for providing the $4,4^{\prime}$-sulfonyldibenzoic acid.

\section{REFERENCES}

1. P. E. Cassidy, "Thermally Stable Polymers, Synthesis and Properties," Dekker, New York, N.Y., 1980.

2. R. B. Seymour and G. S. Krishenbaum, "High Performance Polymers: Their Origin and Development," Elsevier, New York, N.Y., 1986.

3. Y. Kasashima, K. Yamamoto, N. Ando, F. Akutsu, K. Naruchi, and M. Miura, Polym. J., 26, 1298 (1994).

4. Y. Kasashima, H. Kumada, K. Yamamoto, F. Akutsu, K Naruchi, and M. Miura, Polymer, 36, 645 (1995).

5. F. Akutsu, K. Takahashi, Y. Kasashima, M. Inoki, and K. Naruchi, Macromol. Rapid Commun., 16, 495 (1995).

6. C. C. Price and G. P. Mueller, J. Am. Chem. Soc., 66, 632 (1944).

7. P. W. Morgan, "Condensation Polymers by Interfacial and Solution Methods," Interscience, New York, N.Y., 1965.

8. F. Akutsu, S. Yoshioka, Y. Suzuki, K. Naruchi, M. Miura, and K. Nagakubo, Macromol. Rapid Commun., 8, 113 (1987).

9. F. Akutsu, H. Nemoto, K. Naruchi, M. Miura, and K. Nagakubo, Macromol. Rapid Commun., 10, 237 (1989).

10. S. Nishizaki, S. Eto, T. Moriwaki, Kogyo Kagaku Zasshi, 71, 1116 (1968), [Chem. Abstr., 69, 97269e (1968)].

11. H. Manami, M. Nakazawa, Y. Oishi, M. Kakimoto, and Y. Imai, J. Polym. Sci., A, Polym. Chem., 28, 465 (1990). 